\title{
Thwack of Worldwide Weather Transformation on Vector and Vector-Borne Parasitic Infections
}

\author{
Deepak Sumbria $^{1 *}$, L. D. Singla ${ }^{2}$ \\ ${ }^{I}$ Department of Veterinary Parasitology, Post-Graduate Institute of Veterinary Education \& Research \\ (PGIVER), India \\ ${ }^{2}$ Department of Veterinary Parasitology, College of Veterinary Sciences, Guru Angad Dev Veterinary and \\ Animal Sciences University, India
}

*Corresponding Author: Deepak Sumbria, Department of Veterinary Parasitology, Post-Graduate Institute of Veterinary Education \& Research (PGIVER), India, Email: sumbria.deepak31@ gmail.com

\begin{abstract}
Debatably one of the most important effects of environment transformation is the potential impact on human and animal health. The substantiation that environment warming is changing the distribution of arthropods vectors and the pathogens they transmit is reviewed and assessed. The principal looms are either phenomenological, which typically presume that environment alone limits existing and future distributions, or mechanistic, asking which arthropod-demographic restriction is affected by specific abiotic situation. By 2100 it is estimated that average worldwide warmth will have risen by $1.0-3.5^{\circ} \mathrm{C}$, increasing the likelihood of many vector-borne diseases in new areas. Vector-borne animal diseases sham a continuous and substantial danger to livestock economies around the world. Escalating intercontinental voyage, the globalization of deal, and environment transformation are likely to play an increasingly more significant role in the opening, establishment and transmission of arthropod-borne disease worldwide. Higher temperature may be connected with increased insect abundance-thereby amplifying the risk of disease transmission. Most important disease at par are malaria, leishmania, trypanosomiasis, chagas, babesiosis, filariasis, onchocerciasis, loaiasis and heart worm infection, so attempts to be made to reduce the chance of global warming and save our future.
\end{abstract}

Keywords: Global-warming, vector-borne diseases, parasites, livestock, human-beings

\section{INTRODUCTION}

One of the environmental threats our globe faces today is the potential for long term change in the earth's climate patterns known as 'global climate change (GCC)'. According to United Nations Framework Convention on Climate Change (UNFCCC) "a change of climate which is attributed directly or indirectly to human activity that alters the composition of the global atmosphere and which is in addition to natural climate variability observed over comparable time periods" [1]. Examples of GCC are global warming, changes in rainfall patterns, and changes in the frequency of extreme weather events. The global warming is different from global climate change which mean's an increase in Earth's average surface temperature [2]. Environment transformation may occur due to in-house natural procedure or outside forcing, or to constant anthropogenic alteration in the composition of the atmosphere or in ground use so the usual basic factors, such as alteration in the solar power strength or sluggish alteration in the Earth's path in the solar system; natural procedure within the environment structure (e.g. alteration in sea motion); person actions that cause alteration the air composition (e.g. via using of fossil fuels) and the ground surface (e.g. cutting of plants, making of more cities etc.) [3]. In order to understand why global climate change occurring, it helps to understand what is occurs in the earth's atmosphere [1]. The earth's atmosphere consists mainly of mainly nitrogen and oxygen, with small amount of hydrogen, helium, argon, neon and other gases. The greenhouse gases play an important role in determining the climate and climate change. A greenhouse gases is a gas that traps infrared energy (heat) in the atmosphere [4]. Carbon dioxide i.e. $\mathrm{CO}_{2}$ (sources: fossil fuel combustion and land use changes), Methane i.e. $\mathrm{CH}_{4}$ (sources: arable farming and livestock production), Nitrous oxide i.e. $\mathrm{N}_{2} \mathrm{O}$ (sources: arable farming and water incineration) and chlorofluorocarbon i.e. CFC-12 and CFC-11are major greenhouse gases. The relative heat 
trapping ability of $\mathrm{CO}_{2}, \mathrm{CH}_{4}, \mathrm{~N}_{2} \mathrm{O}$ and $\mathrm{CFC}$ are $1,23,296$, and 12,000 respectively [2]. Sources of global atmospheric concentrations of $\mathrm{CO}_{2}$ percentage from burning of fossil fuels is about $49 \%$, industrial process is $24 \%$, deforestation is $14 \%$ and agriculture is $13 \%$. Global atmospheric concentrations of $\mathrm{CO}_{2}, \mathrm{CH}_{4}$ and $\mathrm{N}_{2} \mathrm{O}$ have increased markedly as a result of human activities since 1750 and now far exceed preindustrial values determined from ice cores spanning many thousands of year concentrations of $\mathrm{CO}_{2}$ have increased from $280 \mathrm{ppm}$ (preindustrial value) to $390.5 \mathrm{ppm}$ Jan $2012, \mathrm{CH}_{4}$ from $700 \mathrm{ppb}$ to $1871 \mathrm{ppb}, \mathrm{N}_{2} 0$ from 270 to $323 p p b$, CFC-11 from 0 to 241ppt in 2012 [5]. So the Carbon dioxide $\left(\mathrm{CO}_{2}\right)$, methane $\left(\mathrm{CH}_{4}\right)$, nitrous oxide $\left(\mathrm{N}_{2} \mathrm{O}\right), \mathrm{CFC}-12$ and $\mathrm{CFC}-11$ are considered to be the major greenhouse gases as they are continuously increasing in concentration since1978 [6].

In order to make Earth as a livable planet the occurrence of greenhouse gases in the environment is a natural part of the atmospheric system. But generally these gases are more transparent to incoming solar emission, which in turn causes the sun's power to pass through the climate and reach to the earth surface [6]. As a result of this process the solar energy is absorbed on ground surface, and used in reaction like photosynthesis by plants, or returned back to space as infrared rays. So, at last some of these rays passes the environment and goes back to space, whereas some is engrossed by greenhouse gas molecules and then re-emitted in all directions [3]. As a result the Earth's surface temperature goes up and it became a threat to melting of polar ice bergs also. Major greenhouse gases are Methane $\left(\mathrm{CH}_{4}\right)$, nitrous oxide $\left(\mathrm{N}_{2} \mathrm{O}\right)$, chlorofluorocarbons (CFCs) which have a strong warming effect due to its heat-trapping abilities [7]. Earth's normal average temperature would be $-0.4^{\circ} \mathrm{F}\left(-18^{\circ} \mathrm{C}\right)$, rather than the present $59^{\circ} \mathrm{F}\left(15^{\circ} \mathrm{C}\right)$ in the absence of this greenhouse effect,). So the warming of the climate system is unequivocal, as it is now evident from observations of increases in global average air and ocean temperatures, widespread melting of snow and ice and rising global average sea level [8]. Most of the observed increase in global average temperatures since the mid-20th century is very likely due to the observed increase in anthropogenic GHG concentrations. The IPCC predicted that climate change will become apparent in the following main ways: by around 2100 global temperatures will have risen by between $1.1-6.4^{\circ} \mathrm{C}$, in the course of the present century sea levels will rise by between 18-59 centimeters [2].

The maximum effect of environment change on transmission is likely to be observed at the extremes of the range of temperatures at which the transmission may occur [4]. Malaria and dengue fever are among the most important vector-borne diseases in the tropics and subtropics; Lyme disease is the most common vector-borne disease in the USA and Europe [3]. Encephalitis is also becoming a public health concern. By 2050 it is approximated that the Sahara and the semi-arid parts of southern Africa may get warm by $1.6{ }^{\circ} \mathrm{C}$, while equatorial countries such as Cameroon, Kenya and Uganda could experience rises of $1.4{ }^{\circ} \mathrm{C}$ [8]. Climate oscillations can affect the dynamics of dengue fever [5], which is transmitted by the predominantly urban mosquito Aedes aegypti. In Latin America, about $78 \%$ of the inhabitants around 81 million public live in urban settlements and the disease has been on the increase in the past decade [9].

Many reason can explain the climate changes, among which all most all are some ware related to human, such as the rise in commercial transportation, but also owners traveling with their pet during the holidays, the expansion of "outdoor" activities [3], the increase of individual housings with gardens; the ignorance of the risks, linked to animals in general and to wildlife in particular; ecological transformation like forest breakup, establishment of parks; the increase of wild mammal populations [10]. Environment transformation is a reality which may explain the increase of density of arthropod vectors, but also of their hosts, changes in periods of activity and variations in geographical distribution. Universal warming has speeded up over the last hundred years with an average gain of $0.74{ }^{\circ} \mathrm{C}$ in 100 years [11]. Dermacentor reticulatus, the tick vector of canine babesiosis caused by Babesia canis, is present in $2 / 3$ of the French territory [12]. It is undoubtedly scattering to the East, favoring milder winters. It has now been documented in Belgium [13], the Netherlands, where cases of canine babesiosis have become more and more frequent, it has also been observed in other country like Germany, Czech Republic and Slovakia [14, 15]. In Slovakia, field studies showed that its limited area of presence had gained $200 \mathrm{~km}$ north since 1970s, as well as 300 
$m$ in altitude [16]. These studies conducted have exposed that shorter winters have a straight blow on the ecosystem of ticks. Concerning Ixodes ricinus, its occurrence and density are obviously related to the plant cover, but also to the density of its hosts: micro mammals for larvae and nymphs and large mammals for adult ticks [10]. Ixodes scapularis is highly vulnerable to desiccation when relative humidity drops below approximately 90\% [17]. Even a few hours at stumpy humidity can be deadly, but ticks returned to humid air may bear petite mortality [18]. Low relative humidity (50\%) allows survival when temperatures are below 58 ${ }^{\circ} \mathrm{C}$, but relative humidity above $70 \%$ is required when temperatures exceed $150{ }^{\circ} \mathrm{C}$. Even short term exposure to extreme cold (e.g. below -15 $\left.{ }^{\circ} \mathrm{C}\right)$ can be lethal to I. scapularis $[19,20]$ and $I$. ricinus [21] so cold winter weather could be responsible for a significant amount of mortality, and might constrain Ixodes populations.

The overall effects of global climate change are likely to be harmful. Humans and animals could suffer from increased spread of infectious diseases, heat related deaths, and air pollution [10]. Global climate change and increased climatic variability are particularly likely to affect vector and vector borne parasitic diseases. Temperature, precipitation, humidity, and other climatic factors are known to affect the reproduction, development, behavior, and population dynamics of the arthropod vectors of these diseases [22].

\section{Impact of Global Climate Change on VECTOR-BORNE PARASITIC DISEASES}

The diseases that are transmitted by arthropod (flies, ticks, bugs etc) are knows as Vectorborne diseases (VBDs). Almost half of the world's inhabitants, which subsist in the tropical and subtropical areas of the globe i.e. mainly in the developing country, are affected by theses disease, it may lead to high cause of morbidity and mortality between them [9]. It has been documented that CBDS infection lead to 1.5 million (approximate) human deaths/year [7]. But many infection of parasitic disease like Onchocerciasis and Lymphatic filariasis remain unreported, it may be due communication gap or religious blockage. The ecological allocation of both vectors and their reservoir hosts effect the geological allocation of VBDs. Mainly all vectors want to have hot and humid environment because they are cold-blooded organism so they can't regulate their own internal temperature and therefore rely on outer environment [13]. In order to complete life cycle parasite need vectors, they can also act as the main mode of transmission of infection [17]. Mainly in VBDs transmission is of two types: Anthroponotic infections or human-vectorhuman transmissions, in this type human beings act as reservoir of the disease. While in other type i.e. Zoonotic infections or animal-vectorhuman transmission, animals are the reservoir and human being are considered secondary hosts and do not normally add to the disease diffusion cycle as their levels of circulating pathogen are often too low to help maintain transmission [5, 7]. Anthroponotic infectivity can hypothetically be eliminated if all human cases of the disease are cured; while on other hand control of zoonotic diseases is difficult because all animal reservoirs of the infection would need to be treated [13].

\section{Vector-borne Disease Dynamics}

For the spreading of VBD there should be 3 things: first is the susceptible population in which the disease can spread, second is the vector which can spread the infection and third is the parasitic organism which can cause the disease. In hot and humid countries environmental condition are favorable, which are required for survival and reproduction of both vector and parasite [3]. In a parasitic prone area even if all conditions are good for the propagation of disease then also it can be controlled if we have better health programs [20]. All these parameters are more or less related to increase in the environmental temperature [23]. Improved temperature level can reduce the development time of some arthropod species [20].

\section{Direct Effects of Climate Change on Vector- borne Disease}

Climate change has the potential to: Increase range or abundance of animal reservoirs and/or arthropod vectors (e.g., Malaria, Schistosomiasis). Enhance transmission (e.g., West Nile virus and other Arbo viruses). Increase importation of vectors or pathogens (e.g., Dengue, Chikungunya). Increased animal disease risk lead to potential human disease risk (e.g., African trypanosomiasis) [24]. 
Temperature Effects on Vectors and Pathogens

Vector- Temperature can enhance or reduce any vector population like Hyalomma tick prefer hot temperature while Bhoophilus tick prefer less hot temperatures [8]. It can also alter the vulnerability of vectors for some parasitic agents [7]. Alterations in temperature can transform in the rate of vector growth, feeding rate and host contact can be altered moreover it can also transform the seasonality of inhabitants. Temperature and moisture modulate key events in the life cycle of Culicoides vectors, and climate change-related alterations of these environmental variables have the potential to (1) increase the range, abundance and seasonal activity of the vector, (2) increase the proportion of competent vector individuals, and (3) increase the development rates of the virus within the vector. Outbreaks of West Nile and St. Louis encephalitis viruses are associated with above average summer temperatures

Pathogen- In hot temperatures there is reduced extrinsic incubation era of the parasite which is present inside the vector [13].

\section{Effects of changes in rainfall on vector and vector-borne pathogens}

Vector- Change in the humidity as a result of rainfall may enhance larval territory and also effect vector population like Hyalomma tick prefer less humid area while Bhoophilus tick prefer more humid area. But sometime excessive rainfall can also lead to flood like situation which in turn cause decrease in vector population [7]. It is also seen that sometime low rainfall can generate favorable condition for the vector habitat, so pools can be formed due to excessive drying of small river which can act as conductive place for malaria parasite. It can also lead to water storage in small container by human which in turn became a good place for the propagation of the mosquitoes. Generally it is seen that enhanced humidity increases vector survival and reduced humidity level decreases vector survival rate [11].

Pathogen- Development of Plasmodium inside anopheline mosquito can be effected by humidity [19].

Increased sea level effects on selected vectorborne pathogens- Changed flow and salt marshes are associated with mosquito species

ARC Journal of Animal and Veterinary Sciences elimination because there is reduction in mosquito breeding-sites (e.g. reduced habitat for Culiseta melanura) [23].

Vector Activity- Humidity and precipitation can also have a significant role in vector activity. A higher relative humidity can increase vector activity, but heavy rainfall can actually decrease activity. Increased activity increases transmission rates [24].

\section{Vector Survival}

Relationship between temperature and vector mortality is quadratic: mortality rates increase at high and low temperatures. Temperature effects on development may affect mortality rates: particularly high rates of development of mosquitoes can result in small adults with poorer survival [9]. This is one example where the terms in epidemiological models of VBDs interact with one another. Another important interaction is the dependence of transmission coefficients for tick-borne pathogens on the numbers of vectors feeding on the host [23]. The understanding of such interactions is, however, largely rudimentary. When relative humidity is low, ticks have to make more frequent, energyexpensive trips to the litter layer to rehydrate. High "monsoon" rainfall knocks ticks off the herbage and prevents them from finding a host. Lower humidity increase the energy requirement for host seeking by ticks shortening their lives. Lower rainfall decrease breeding areas for mosquitoes, compounded by density-dependent intra-specific competition among the larvae [25].

\section{Vector and Host Seasonality}

In parasitic infection seasons play a very crucial role in the interaction between vectors and hosts mainly in case of zoonotic infection having life cycle sustained in wildlife. In this case both host and vector are affected by seasonal alteration in environment and weather independent effects like day length [7]. The lifecycle and activity level of the host along with vector can be affected as well. It depends upon how fast immune animals die and how fast uninfected animals are borne [26]. There are many VBDs of concern, especially in developing countries, a number of which are on the WHO list of neglected tropical diseases (including Leishmaniasis , Trypanosomiasis, Chagas, Lymphatic filariasis, and Onchocerciasis) Table no.1 [7] because they occur in areas where 
poverty is the most significant risk factor for their occurrence.

Table1. Information of major parasitic diseases

\begin{tabular}{|c|c|c|}
\hline Disease & Pathogen & Vector \\
\hline Malaria & $\begin{array}{c}\text { Plasmodium } \\
\text { falciparum, } P \text {. } \\
\text { vivax, P. ovale, } \\
P . \text { malariae }\end{array}$ & $\begin{array}{l}\text { Anopheles } \\
\text { spp. } \\
\text { Mosquitoes }\end{array}$ \\
\hline Leishmaniasis * & $\begin{array}{l}\text { Leishmania } \\
\text { spp. }\end{array}$ & $\begin{array}{c}\text { Lutzomyia \& } \\
\text { Phlebotomus } \\
\text { spp. } \\
\text { Sandflies }\end{array}$ \\
\hline $\begin{array}{c}\text { African } \\
\text { Trypanosomiasis } \\
*\end{array}$ & $\begin{array}{l}\text { Trypanosoma } \\
\text { brucei } \\
\text { gambiense, } T \text {. } \\
\text { b. rhodesiense }\end{array}$ & $\begin{array}{c}\text { Glossina } \\
\text { spp. } \\
\text { (tsetse fly) }\end{array}$ \\
\hline Chagas disease * & $\begin{array}{c}\text { Trypanosoma } \\
\text { cruzi }\end{array}$ & $\begin{array}{c}\text { Triatomine } \\
\text { spp. }\end{array}$ \\
\hline Babesiosis & $\begin{array}{c}\text { Babesia } \\
\text { microti, } B . \\
\text { divergens, }\end{array}$ & Ixodid tick \\
\hline $\begin{array}{l}\text { Lymphatic } \\
\text { filariasis* }\end{array}$ & $\begin{array}{c}\text { Wucheria } \\
\text { bancrofti, } \\
\text { Brugia malayi }\end{array}$ & Mosquito \\
\hline Onchocerciasis* & $\begin{array}{c}\text { Onchocerca } \\
\text { volvulus }\end{array}$ & Black flies \\
\hline Loaiasis & Loa loa & $\begin{array}{c}\text { Tabanid } \\
\text { flies }\end{array}$ \\
\hline Heart worm & $\begin{array}{l}\text { Dirofilaria } \\
\text { immitis, } D \text {. } \\
\text { repens } \\
\end{array}$ & Mosquitoes \\
\hline
\end{tabular}

* WHO neglected tropical disease

\section{Malaria}

There are approximate, more than 3,500 species of mosquitoes (Diptera: Culicidae) [4, 27]. By means of new thermal sensitivities, malaria transmission has recently been predicted to peak at $25{ }^{\circ} \mathrm{C}$ (dramatically lower than previous predictions) and decline significantly above 28 ${ }^{\circ} \mathrm{C}$ [28]. Approximately $40 \%$ of the world's population lives in areas which are at risk for malaria. Every year about 500 million people become severely ill from malaria. Between 700,000 and 2.7 million mostly children in subSaharan Africa die each year due to malaria [7]. While most of the increase is predicted to occur in Africa, some increased risk is projected in Britain, Australia, India and Portugal. IPCC predicts that the global population at risk for malaria will increase by $220-400$ in the next century. Malaria is an extremely climate sensitive disease [9]. Clearly transmission does not occur in climates where mosquitoes cannot survive.

Malaria is a mosquito-borne infectious disease caused by parasitic protozoans of the genus
Plasmodium (vivax, malariae, ovale, knowlesi and falciparum) and is transmitted by female mosquito vectors of the Anopheles species [13]. Following the worldwide Malaria eradication program launched by the WHO in the 1950s, 79 countries have eradicated malaria. Between 2000-2010 the incidence of malaria has fallen by $17 \%$ globally and by $33 \%$ in the African regions. There were 655,000 reported malaria deaths in 2010, out of which $86 \%$ were of children under 5 year of age [29]. Optimal larval development occurs at $28^{\circ} \mathrm{C}$ and optimal adult development between 28 and $32^{\circ} \mathrm{C}$. Transmission cannot occur below $16^{\circ} \mathrm{C}$ or above $33^{\circ} \mathrm{C}$ as sporogony (the production of sporozoites which comprises dissemination and development of the parasite in the vector) cannot take place. Vectorial capacity of mosquitoes increases as temperature increases (optimal temperature between $22-30^{\circ} \mathrm{C}$ ) [6]. Generally mosquito lifespan increases with higher temperatures. Females increase blood meal frequency at higher temperatures. Aquatic life cycle of mosquitoes reduced from 20 to 7 days. Transmission cannot occur below $16^{\circ} \mathrm{C}$ or above $33^{\circ} \mathrm{C}$ as sporogony (the production of sporozoites which comprises dissemination and development of the parasite in the vector) cannot take place. Plasmodium species grow faster at higher temperatures (optimal between $27-30^{\circ} \mathrm{C}$ ) [13]. The minimum temperature required for development of Plasmodium vivax parasite in anopheline mosquitoes ranges from 14.5-16.5 ${ }^{\circ} \mathrm{C}$, while for Plasmodium falciparum it ranges from $16.5-19{ }^{\circ} \mathrm{C}$. However, the best conditions for development of the malaria parasite are $20-30{ }^{\circ} \mathrm{C}$ temperature and $60 \%$ relative humidity $(\mathrm{RH})$ [30].

Dengue is a another important mosquito-borne disease in humans, caused by a virus of the Flavi virus genus, Flaviviridae family affecting about 390 million people each year, through the years 2008-2012, dengue fever cases were reported in several Mediterranean (and Adriatic) countries: Greece, Croatia, Italy, Malta, France, Spain and Portugal [31]. Although most cases were probably imported, in 2010 local transmission of dengue was reported in both Croatia and France [31]. Today, there is an apparent threat of dengue outbreaks in the Mediterranean European countries [9, 31].

\section{Leishmaniasis}

It is endemic in warmer part of the world covering almost 88 countries (16 developed and 72 developing countries) around the globe. It is 
estimated that 2 million new cases occur yearly (1.5 million for cutaneous leishmaniasis and 500,000 for visceral leishmaniasis) and that 12 million people are infected worldwide [32]. It was noticed that $P$. papatasi were less active in temperature of $11-20{ }^{\circ} \mathrm{C}$ and $37-40{ }^{\circ} \mathrm{C}$, moreover preferred range to temperature for this sand fly is $32-36{ }^{\circ} \mathrm{C}$ [33]. This sand fly prefer hot temperature so it was active in dry season (May to November), so in turn its activity peaks were recorded in between May and November [31].

Out of 5 lakhs cases of VL, more than 90 percent are reported from India, Bangladesh, southern Sudan, Nepal and northeast Brazil [23]. Climate directly affect the growth of sand fly and distribution of VL disease, in addition to it climate also has indirect impacts on disease transmission or sand fly by influencing-

1. The distribution of hosts, 2. The local vegetation (important as resting sites and sugar sources),

\section{Possible impact of future climate risks}

The rises in temperature in day time and humidity level during night time have greatly influenced the growth of flies and the distribution of leishmaniasis but in the cold climatic countries the prevalence is limited because the growth of fly is limited and they are not able to suck the blood in night [14]. High level of precipitation (rain) has also played very important role in the spreading of disease, flooding may spread the vector of disease and the larvae of fly to distant and non infected areas also. In some parts of Latin America, deforestation has led to an increase in leishmaniasis [13]. The former forest has been replaced by areas of farmland, interspersed with patches of forest. With growth of the fox population, an excellent reservoir host of visceral leishmaniasis, Kala-Azar has increased and the sylvatic leishmaniasisvector sand flies have become peri-domestic [25]. In the Amazon region, human populations, accompanied by their infected dogs, have immigrated, serving to increase the prevalence of leishmaniasis. Recent studies have highlighted the spreading of the leishmaniasis, as they accompany the movement of the phlebotomine vectors into previously free areas as suggested for the spread of canine leishmaniasis from southern to northern Italy [26] and from northern to southern Brazil [34]. Indeed, canine leishmaniasis is now well established in South America as far south as northern Argentina [35]. Global warming could prompt the establishment of canine leishmaniasis in areas such as the United Kingdom, where the vectors are currently absent, but where Leishmania infantum infected dogs that had travelled to endemic areas are present [36].

\section{Dirofilariasis}

Dirofilariasis is a mosquito borne filarial nematodal diseases caused by Genus Dirofilaria. The transmission of Dirofilaria occurs by mosquito of the genera Anopheles, Aedes and culex. Dirofilaria is a common parasite of domestic and wild carnivores mainly the canines. It is considered to be a great hazard for the dogs of tropical, subtropical and in some temperate countries [3]. They may cause zoonotic filarial infection in man producing various pathological lesions in the lung, heart, subcutaneous tissue and conjunctiva. Diofilaria immitis is a common parasite of dog in many tropical, subtropical and warm temperate areas of the world mainly distributed in the United States, Mediterranean countries of Europe and Africa, Pacific islands, South-East Asia including India, and Japan, and Australia. While Dirofilaria repens is commonly distributed in United States, Europe, Africa, India and Sri Lanka [14]. However human dirofilariasis have been reported from France, Italy, Greece, and other countries of Europe and less commonly from Israel, Africa, and Sri Lanka [9]. Dirofilariasis is a mosquito borne parasitic diseases therefore climate suitable for breeding of mosquito is the time of occurrence of this type of parasitic diseases [13]. The mosquito are abundant in the warmer climate therefore new cases become available during this period at the same time dog population of a particular area is an important factors for maintenance of this parasite in that area [37]. Temperature, precipitation, and relative humidity are the three main factors that determine the abundance of mosquitoes and the prevalence of mosquitoborne Dirofilaria infection. The optimum temperature for mosquito development of tropical/temperate species is $25-27.8^{\circ} \mathrm{C}$. For Dirofilaria infection climate based models that determine the effect of temperature on the extrinsic incubation of larval stage in Aeopheles albopictus the development from microfilaria stage to infective larvae takes 14-18 days at $26.8^{0} \mathrm{C}$ for $D$. immitis and $16-18$ days for $D$. repens [38]. The global worming projected by the IPCC suggested that warm summer is suitable for Dirofilaria transmission and that will be the rule in the further decades and if the 
actual trend of temperature increase continue filarial infection should spread into previous infection free area. These factors not only favor incubation of Dirofilaria but also impact on mosquito species [21].

It is implicit by the models that 130 DUs (heartworm Development Unit) are necessary per year for the parasite to maintain itself in one same area [11]. Therefore, it seems that heartworm disease can now be maintained beyond the Mediterranean region, based only on the biology of vectors and parasites and the evolution of temperatures [39]. Typical weather transformation may be reflected by an increase in the number of days of activity per year. This is actually happening now with the expansion across Europe of the tiger mosquito, Aedes albopictus, which was imported from Asia to Italy in 1990 through a trade of old, tires for the remolding industry [40]. Today, it has been reported as far as in the Netherlands. Arriving from Italy to France via Nice, it is now present in approximately $1 / 3$ of the southern French territory, up to Lyon [10]. This mosquito is a competent host for $D$. immitis, with a rapid development to infective $\mathrm{L}_{3}$. It is also a more violent and diurnal vector than our autochthonous mosquitoes (Culex spp.). It is worth noting that this mosquito plays a significant role in human medicine since it is the main vector of dengue and chikungunya viruses in subtropical areas.

\section{Chagas disease or American Trypanosomiasis}

It is estimated that over 7 million people are infected and 109 million individuals are at risk of infection in Latin America [41]. Changes in land use, deforestation and movement of human populations can also bring people into contact with potential wild triatomine vectors [42] that might incidentally assume to play a primary role in T. cruzi transmission. For Triatoma infection animals such as dogs, cats, armadillos, opossums and rodents serve as host reservoirs in region of Central and South America [27]. In Amazon forest region of Brazil risk for Chagas disease is increasing due deforestation and urban colonization, thus changing the equilibrium between reservoir hosts and wild vectors [13].

\section{African Trypanosomiasis}

Trypanosomiasis, spread by tsetse flies, imposes a huge burden on African people and livestock
[9]. Many aspects of the vectors' life cycles are sensitive to climate, and spatial distributions can be predicted using satellite-derived proxies for climate variables. Sleeping sickness is found in remote sub-Saharan areas where health systems are often weak. T. b. gambiense is endemic in 24 countries of west and central Africa and causes more than $90 \%$ of reported cases of sleeping sickness. T. $b$. rhodesiense is endemic in 13 countries of eastern and southern Africa, representing less than $10 \%$ of reported cases [32]. The transmission of African trypanosomiasis follows an animal-vectoranimal transmission cycle with occasional spillover into humans. T. b. gambiense sleeping sickness is transmitted from human to human by the tsetse fly and is the most common form of transmission of this disease [13]. As some animals can host the human pathogenic parasite, transmission can occasionally take place directly from animals to humans, which is believed to be one of the potential mechanisms of the longterm maintenance of the disease in endemic areas [21]. The length of the Glossina pupal development period decreases with increasing temperature, whereas larval production decreases above a certain threshold, and both pupal and adult mortality increase with temperature [33]. The minimum temperature required for development of $T . b$. rhodesiense is predicted to be $20.7-26.18^{\circ} \mathrm{C}$ with G. pallidipes and for T. b. gambiense $20.9-25.68{ }^{\circ} \mathrm{C}$ in $G$. morsitans. After deforestation the land is used for 2 purpose one is either colonization and other is making fields for crop/plant cultivation, if fields for crop/plant cultivation are made then tall crops such as cocoa, coffee, oil palms and mangoes are grown these tall corps/plant provide comfortable habitats for tsetse fly population [29]. So for crop cultivation when ever human come for ploughing of field they became more vulnerable to infection. It was noticed that in some region of African like Sahel zone these mainly like the river banks mainly in rainy season, but during dry season they migrate to the forests [5].

\section{ADAPTATION STRATEgies}

Adaptation Strategies to be adopted for reducing the climate related vector and vector-borne parasitic diseases- Decision Support ToolsEnhance early warning systems based on climate and environmental data for selected diseases [13]. Surveillance and MonitoringEnhance vector surveillance and control 
programs and monitor disease occurrence. Technology Development- Develop vaccines for vector and other vector-borne diseases, Develop more rapid diagnostic tests, Deploying low-cost, low-tech solutions like mosquito nets and water filters ,Using satellite data and geographical information systems to feed into surveillance systems. Infrastructure development- Consider possible impacts of infrastructure development such as water storage tanks [40]. Anticipating the potential for new and emergent VBD pathogens and their potential to change the current VBD burden. All countries should make polices for serious attempts to mitigate global warming [13]. The following adaptation measures are recommended: 1) to go beyond empirical observations of the association between climate change and infectious diseases and develop more scientific explanations, 2) to improve the prediction of spatial-temporal process of climate change and the associated shifts in infectious diseases at various spatial and temporal scales, and 3) to establish locally effective early warning systems for the health effects of predicated climate change [43, 44]. Outlining improvement and adaptation measures can be used specifically in the livestock sector to minimize the impacts of climate changeassociated livestock diseases [45].

\section{Conclusion}

Warming of the climate system is unequivocal. Continued GHG emissions at or above current rates would cause further warming and induce many changes in the global climate system during the $21^{\text {st }}$ century that would very likely be larger than those observed during the $20^{\text {th }}$ century. Climate change will affect the distribution and incidence of VBD globally.

\section{REFERENCES}

[1] IPCC., Glossary of terms In: Managing the Risks of Extreme Events and Disasters to Advance Climate Change Adaptation [Field, C.B., V. Barros, T.F. Stocker, D. Qin, D.J. Dokken, K.L. Ebi, M.D. Mastrandrea, K.J. Mach, G.K. Plattner, S.K. Allen, M. Tignor, and P.M. Midgley (eds.)]. A Special Report of Working Groups I and II of the Intergovernmental Panel on Climate Change (IPCC). Cambridge University Press, Cambridge, UK, and New York, NY, USA, pp. 555-564 (2012).

[2] IPCC., Fourth Assessment Report: Climate Change 2007. Working Group I: The Physical Science Basis. IPCC, 2001. ch: 3: The Carbon Cycle and Atmospheric Carbon Dioxide
Executive Summary, in IPCC TAR WG1 (2007).

[3] Genchi C., Rinaldi L., Mortarino M., Genchi M. and Cringoli., Climate and Dirofilaria infection in Europe. Vet. Parasitol. 163, 286292 (2009).

[4] Elbers A.R.W, Koenraadt C.J.M. \& Meiswinkel R. Mosquitoes and Culicoides biting midges: vector range and the influence of climate change. Rev. Sci. Tech. Off. Int. Epiz., 2015, 34 (1), 123-137

[5] Hunter P. R., Climate change and waterborne and vector-borne disease. J. Applied Microbiol. 94, 37-46 (2003).

[6] Kulshrestha U. C., 2012. Global warmingPresent status of research and future strategies. J. Ind. Geophys. Union .16(4), 143-160 (2012).

[7] Hill C. A., Kafatos F. C., Stansfield S. K. and Collins F. H., Arthropod-borne diseases: Vector control in the genomics era. Nature Reviews Microbiol. 3, 262-268 (2005).

[8] Githeko A. K., Lindsay S. W., Confalonieri U. E and Patz J. A., Climate change and vectorborne diseases: a regional analysis. Bulletin of the World Health Organization, 78(9), (2000).

[9] J. Dedet and F. Pratlong. Leishmania, Trypanosoma and moxoneous trypanosomatids as emerging opportunistic agents. J. Eukaryot. Microbiol. 47, 37-39 (2000).

[10] F. Beugneta and K. Chalvet-Monfray, Impact of climate change in the epidemiology of vector-borne diseases in domestic carnivores. Comparative Immunology, Microbiology and Infectious Diseases 36 , 559-566 (2013).

[11] J. Semenza and B. Menne. Climate change and infectious diseases in Europe. The Lancet 365375 (2009).

[12] Halos L., Lebert I., Chao I., Vourc'h G., Ducrot C., Abrial D., Ravier J. F. and Guillot J., Questionnaire based survey on distribution and clinical incidence of canine babesiosis in France. BMC Vet. Res. 9, 41, (2013).

[13] Cochez C., Lempereur L., Madder M., Claerebout E., Simons L., DeWilde N., Linden A., Aegerman C., Heyman P. and Losson B., Foci report on indigenous Dermacentor reticulatus populations in Belgium and a preliminary study of associated babesiosis pathogens. Med. Vet. Entomol. 26, 355-358 (2012).

[14] Dautel H., Dippel C., Oehme R., Hartlet K. and Schettler E., Evidence for an increases geographical distribution of Dermacentor reticulatus in Germany and detection of Rickettsia sp.RpA4. Int. J. Medi. Microbiol. 296, 149-156 (2006).

[15] Siroky P., Kubelova M., Bednar M., Modry D., Hubalek Z. and Tkadlec E., The distribution and spreading pattern of Dermacentor 
reticulatus overits threshold area in the Czech Republic-how much is range of this vector expanding? Vet. Parasitol. 183, 130-135 (2011).

[16] Bullova E., Lukan M., Stanko M. and Pet'Ko B., Spatial distribution of Derma-centor reticulatus tick in Slovakia in the beginning of the 21st century. Vet. Parasitol. 165, 357-360 (2009).

[17] Stafford K. C., Survival of immature Ixodesscapularis (Acari, Ixodidae) at different relative humidities. J. Med. Entomol. 31, 310314 (2014).

[18] R. S. Ostfeld and J. L. Brunner. Climate change and Ixodes tick-borne diseases of humans. Phil. Trans. R. Soc. B 370, 51 (2014).

[19] Vandyk J. K., Bartholomew D. M., Rowley W. A. and Platt K. B., Survival of Ixodes scapularis (Acari: Ixodidae) exposed to cold. J. Med. Entomol. 33, 6-10 (1996).

[20] Burks C. S., Stewart R. L., Needham G. R. and Lee R.E., The role of direct chilling injury and inoculative freezing in cold tolerance of Amblyomma americanum, Dermacentor variabilis and Ixodes scapularis. Physiol. Entomol. 21, 44-50 (1996).

[21] MacLeod J., Ixodes ricinus in relation to its physical environment. II. The factors governing survival and activity. Parasitolo.27, 123-144 (1935).

[22] Gage K. L., Burkot T. R., Eisen R. J. and Hayes E.B., 2008. Climate and Vector borne Diseases. Am. J. Prev. Med. 35(5), 436-450 (2008).

[23] Gubler D. J., 2001. Climate variability and change in the United States: potential impacts on vector- and rodent-borne diseases. Environmental Hlth. Persp. 109 (2), 223-233 (2001).

[24] Greer A., Ng V. and Fisman. D., Climate change and infectious diseases in North America: The road ahead. C. M. A. J. 178(6), 715-722 (2008).

[25] D. J. Rogers.. and S. E. Randolph., Trypanosomiasis control: surmounting diminishing returns. Trends in Parasitol. 19, 113-114 (2003).

[26] Otranto D., Capelli G. and Genchi C., Changing distribution patterns of canine vector borne diseases in Italy: leishmaniosis vs. dirofilariosis. Parasites Vect. 2 (1), S2 (2009).

[27] Becker N., Mosquitoes and their control, Springer-Verlag, Heidelberg, Germany. (2010).

[28] Parham P. E., Waldock J., Christophides G. K., Hemming D., Agusto F., Evans K. J., Fefferman N., Gaff H., Gumel A., LaDeau S., Lenhart S., Mickens R. E., Naumova E. N., Ostfeld R. S., Ready P. D., Thomas M. B., Velasco-Hernandez J. and Michael E., Climate, environmental and socio-economic change: weighing up the balance in vectororne disease transmission. Phil. Trans. R. Soc. B 370, 0551 (2013).

[29] Caminade C., Kovats S., Rocklov J., Tompkins A. M., Morse A. P., Colón-González F. J., Stenlund H., Martens P. and Lloyd S.J., Impact of climate change on global malaria distribution. Proc. Natl. Acad. Sci. U S A. 111(9), 3286-3291 (2014).

[30] Bruce-Chwatt L. J., Epidemiology of malaria. In Essential Malariology. London: William Heinemann Medical Books Ltd, 1980, pp. 129168.

[31] Negev M., Paz S., Clermont A., Pri-Or N. G., Shalom U., Yeger T. and Green M. S., Impacts of Climate Change on Vector Borne Diseases in the Mediterranean Basin-Implications for Preparedness and Adaptation Policy. Int. J. Environ. Res. Public Health 12, 6745-6770 (2015).

[32] WHO., First WHO report on neglected tropical diseases: working to overcome the global impact of neglected tropical diseases (2010).

[33] Boussaa S., Guernaoui S., Pesson B. and Boumezzough A., Seasonal fluctuations of Phlebotomine sand fly populations (Diptera: Psychodidae) in the urban area of Marrakech, Morocco. Acta Trop. 95, 86-91 (2005).

[34] Soccol V. T., Castro E. A., Navarro I. T., de Farias M. R., de Souza L. M., Carvalho Y., Bispo S., Membrive N. A., Minozzo J. C., Truppel J., Bueno W. and Luz E., Allochthonous cases of canine visceral leishmaniasis in Paraná, Brazil: epidemiological implications. Rev. Bras. Parasitol. Vet. 18, 46-51(2009).

[35] Salomon O., Sinagra A., Nevot M., Barberian G., Paulin P., Estevez J., Riarte A. and Estevez J., First visceral leishmaniasis focus in Argentina. Mem. Inst. Oswaldo Cruz 103, 109111(2008).

[36] Shaw S. E., Langton D. A. and Hillman T. J., Canine leishmaniosis in the United Kingdom: a zoonotic disease waiting for a vector? Vet. Parasitol. 163, 281-285 (2009).

[37] Parija S. C., Review of Parasitic Zoonoses, A.I.T.B.S. Publisher Distributer, Delhi. pp.463 (1990).

[38] Cancrini G., Pietrobelli M., Regalbono, F. S. A., Tampieri M. P., della-Torre, A.1995. Development of Dirofilaria and Setaria nematodes in Aedes albopictus. Parassitologia 37: 141-145.

[39] Genchi C., Kramer L. and Rivasi F., Dirofilarial infections in Europe. Vect. Borne Zoonot. Dis. 11(10), 1307-1317 (2011).

[40] Depoortere E., Schaffner F., Hendrickx G., Scholte E., Ducheyne E., Medlock J. and Avenell D., ECDC Technical Report, 
Development of Aedes albopictus risk maps, Stockholm, 45 (2009).

[41] OPS., Estimacion cuantitativa de la enfermedad de Chagas en las Americas. Organizacion Panamericana de la Salud, Montevideo, Uruguay (in Spanish) (2006).

[42] Guhl F., Pinto N. and Aguilera G., Sylvatic triatominae: a new challenge in vector control transmission. Mem. Inst. Oswaldo Cruz 104, 71-75 (2009).

[43] Wu X., Lu Y., Zhou S., Chen L. and Xu B., Impact of climate change on human infectious diseases: Empirical evidence and human adaptation. Environ. Int. 86, 14-23(2016).

[44] Cizauskas C. A., Carlson C. J., Burgio K. R., Clements C. F., Dougherty E. R., Harris N. C. and Phillips A.J., Parasite vulnerability to climate change: an evidence-based functional trait approach. R. Soc. open sci. 4: 160535 (2017).

[45] Bett B., Kiunga P., Gachohi J., Sindato C., Mbotha D., Robinson T., Lindahl J. and Grace D., Effects of climate change on the occurrence and distribution of livestock diseases. Prev. Vet. Med. 137, 119-129 (2017).

Citation: Deepak Sumbria, L. D. Singla. Thwack of Worldwide Weather Transformation on Vector and Vector-Borne Parasitic Infections. ARC Journal of Animal and Veterinary Sciences. 2017; 3(2):1-10. doi: dx.doi.org/ 10.20431/2455-2518.0302001.

Copyright: (C) 2017 Authors. This is an open-access article distributed under the terms of the Creative Commons Attribution License, which permits unrestricted use, distribution, and reproduction in any medium, provided the original author and source are credited. 